\title{
Governo das condutas e subjetividades contemporâneas: o biocapital em questão
}

\author{
Government of conducts and contemporary subjectivities: \\ The biocapital under consideration \\ http://dx.doi.org/10.5007/2178-4582.2015v49n2p41
}

\author{
Renata Rodrigues \\ Universidade Federal de Mato Grosso, Cuiabá/MT, Brasil \\ Dolores Galindo \\ Universidade Federal de Mato Grosso, Cuiabá/MT, Brasil \\ Flávia Cristina Silveira Lemos \\ Universidade Federal do Pará, Belém/PA, Brasil \\ Marcos Nalli \\ Universidade Estadual de Londrina, Londrina/PR, Brasil \\ Daniella Soares Santos \\ Universidade de Brasília, Brasília/DF, Brasil
}

\begin{abstract}
Neste artigo, pretende-se analisar a produção do mercado da saúde por meio da indústria farmacêutica, da gestão de riscos/perigos, da venda e compra de serviços biomédicos variados, sob o modelo neoliberal atual. O governo da vida, na biopolítica, que emerge a partir da segunda metade do século XIX, traz o acontecimento gestão da saúde para o primeiro plano das práticas sociais, em nome do fazer viver e do deixar morrer, como parte do acontecimento história da gerência da população. Trata-se de um estudo teórico a partir de operadores históricos genealógicos, baseado em Michel Foucault e em outros autores contemporâneos, os quais analisaram os processos biopolíticos enquanto biocapital, nos termos da governamentalidade neoliberal do empresariamento da vida.
\end{abstract}

Palavras-chave: Biocapital - Biopolítica - Neoliberalismo - Subjetividades - Foucault esumo
This article aims to analyze the production of the healthcare market by the pharmaceutical industry, the risk management/hazards, the sale and purchase of various biomedical services, under the current neoliberal model. The government of life in biopolitics, which emerges from the second half of the nineteenth century, brings health management event to the forefront of social practices, on behalf of making to live and letting to die, as part of the history of population management event. This is a theoretical study from genealogical incumbents, based on Michel Foucault and other contemporary authors, who have analyzed the biopolitical as biocapital processes, pursuant to neoliberal governmentality of entrepreneurship of life.

Keywords: Biocapital - Biopolitics - Neoliberalism - Subjectivities. Foucault.

\section{Introdução}

A genealogia em Michel Foucault (1979) implica problematizar as práticas de saber, de poder e de subjetivação por meio de uma análise histórica. Há uma preocupação em pensar a coexistência dessas práticas e seus efeitos na gestão das populações e dos corpos individuais simultaneamente com o 
objetivo de explicitar como os objetos foram forjados; como não são naturais, portanto, podem ser transformados. Entre as análises de poder, de saber e de subjetivação realizadas por Foucault (2008a; 2008b) está o conceito de biopolítica, que se tornou um importante operador para a interrogação do que se faz na atualidade por meio dos saberes e políticas de governo da vida em nome da saúde e da defesa da sociedade.

A biopolítica tem como função fazer viver e deixar morrer, por meio da criação de estratégias de regulação para intervir no aumento da longevidade, controlar acidentes e eventualidades, melhorar a deficiência genética humana, melhorar e intensificar traços humanos valorados como qualidades e benfazejos à existência da população (FOUCAULT, 1999). A rubrica biocapital tem sido utilizada para balizar uma série de processos que vêm acontecendo nas últimas décadas, em que elementos ditos da natureza adquirem valor e são estruturados em termos econômicos, principalmente com base na emergência histórica do neoliberalismo.

Tal terminologia chama nossa atenção por seu caráter dúbio, uma vez que passou a ser usada tanto como ferramenta de crítica à comercialização irrefletida da vida quanto pelas organizações econômicas que dela se valem, para cálculos biopolíticos. Parece apropriada à racionalidade neoliberal que vivemos. Foucault (2008a) mostra que as sociedades neoliberais surgem quando problemas relativos à saúde, higiene, natalidade, longevidade, raças não podem ser dissociados do âmbito da racionalidade política, no interior da qual eles aparecem e adquirem importância e intensidade.

Com efeito, a palavra biocapital aparece pela primeira vez na literatura científica em 1913, no livro Evolution by cooperation: a study in bioeconomics, do biólogo Reinheimer, mas somente em 1972 sua conceituação é realizada pelo matemático e economista Georgescu-Roegen, a fim de discorrer sobre a manipulação de órgãos que acompanham os seres vivos desde o seu nascimento, bem como a capacidade dos seres humanos em desenvolver técnicas para manipular e vencer algumas restrições biológicas. Entendemos que discorrer sobre economia não se resume à produção de trabalho, mas implica considerar também todos os envolvidos na relação de comercialização como atores importantes.

O liberalismo é uma filosofia política, caracterizada pelos limites que impõe ao poder exercido pelas autoridades políticas (AVELINO, 2013). É ainda uma maneira de organizar a subjetividade e constituir estilos de vida. A emergência do uso do termo biocapital está ligada ao mercado transnacional de capital biológico, e apenas num momento posterior migrou como crítica a esse próprio movimento do qual surge, como evidenciam Gonzáles et al. (2014). 
Também como bem aponta Foucault (2008a; 2008b), o neoliberalismo foi mais que a construção de subjetividades consumidoras e trabalhadoras, pois fabricou subjetivações empreendedoras e que realizam investimentos para gerar renda; nesse contexto, a saúde e a educação de filhos passaram a entrar em um cálculo de investimentos empresariais da vida. De forma similar, Lazzarato (2004) destaca que a relação econômica não se dá somente com o trabalho e com a expropriação do trabalho pela indústria, porém, inclui todos os aspectos da vida, numa relação entre empresa e consumidor que produz serviços, produtos e mundos comuns, onde essa relação se mantém e é possível. Economia e produção de subjetivação estão intimamente ligadas.

Michel Foucault (2008a), em o Nascimento da Biopolitica, havia alertado a respeito da captura neoliberal, na biopolítica, das subjetividades pelo empresariamento da vida em todas as suas esferas. Sob uma racionalidade neoliberal, o governo das condutas assume a característica de uma tecnologia humana que gere a conduta dos outros: governar é agir sobre as pessoas que devem ser consideradas como livres. O neoliberalismo, por sua vez, em suas formas contemporâneas, divisa-se como arte de governar que assume o mercado como instrumento de inteligibilidade, verdade e medida da sociedade (FOUCAULT, 2008a; LAZZARATO, 2013).

Nessa forma de governo, a população - entendida como um objeto técnico-político - é alvo das intervenções e gestões políticas e econômicas orientadas ao mercado mais do que a um Estado que a regularia, como advertia Foucault (1999):

O cálculo dos economistas liberais focou as liberdades com segurança e os negócios entre as nações, as preocupações em evitar a guerra e as crises econômicas e sociais, o controle da balança comercial, a pobreza integrada socialmente, o trabalhador educado para a docilidade e a submissão política e o impedimento das revoltas citadinas e no campo. [...] Nos mecanismos implantados pela biopolítica, vai se tratar, sobretudo, é claro, de previsões, de estimativas estatísticas, de medições globais; vai se tratar, igualmente, não de modificar tal fenômeno em especial, não tanto tal indivíduo, na medida em que é indivíduo, mas, essencialmente, de intervir no nível daquilo que são as determinações desses fenômenos no que eles têm de global. Vai ser preciso modificar, baixar a morbidade; vai ser preciso encompridar a vida; vai ser preciso estimular a natalidade. E trata-se, sobretudo, de estabelecer mecanismos reguladores que, nessa população global com seu campo aleatório, vão poder fixar um equilíbrio, manter uma média, estabelecer uma espécie de homeostase, assegurar compensações; em suma, de instalar mecanismos de previdência em torno desse aleatório que é inerente a uma população de seres vivos, de otimizar, se vocês preferirem um estado de vida. (FOUCAULT, 1999, p. 293-294). 
Este artigo visa a problematizar a medicalização da vida numa sociedade organizada pela biocapital, em que o empresariamento da saúde ganha vulto no neoliberalismo e produz efeitos na formação de subjetividades, cada vez mais constituídas pela lógica de empresarial de investimentos preventivos. Trata-se de um fazer viver pelo governo do risco/perigo, no campo da seguridade como mercado de direitos, do temer/precaver no mercado em torno da securitização (CASTIEL; ÁLVAREZ-DARDET, 2007).

\section{Mercado brasileiro da saúde e os efeitos do biocapital}

No Brasil, atualmente, há um projeto de expansão da indústria famarcêutica, em correlação com um mercado de patentes na pesquisa de encomenda empresarial, paralelamente à tentativa de realizar parcerias público-privadas entre empresas farmacêuticas e o Sistema Único de Saúde (SUS), para o fornecimento de drogas e diagnósticos moleculares e genéticos preditivos de doenças; além dessas práticas, o Poder Legislativo, o Executivo e o Judiciário estão sendo pressionados pelo setor privado a quebrarem as barreiras éticas de controle de medicamentos, no país, a fim de ampliar um mercado já crescente.

O Ministério da Saúde vem sendo pressionado, juntamente com o Ministério de Ciência e Tecnologia, as agências de controles de medicamentos, como a ANVISA e os conselhos de direitos, para aceitarem a flexibilização das regras de aprovação de novos medicamentos e de sua distribuição. A criação de patentes para os remédios e diagnósticos fabricados no Brasil vem também nesse pacote de encomendas realizadas, na mercantilização da pesquisa e na formação de estudiosos tecnicistas que aceitam esse tipo de trabalho imaterial utilitarista.

Um currículo universitário baseado na teoria do capital humano ganha notoriedade entre os que comercializam o conhecimento e buscam aplicá-lo, instrumentalmente, no mercado da saúde e da educação empresarial. O marketing do biocapital se materializa na chamada rentabilidade da denominada inovação biotecnológica, a ser patenteada e transformada em lucro internacional. Subjetividades empreendedoras de saúde, pelas tecnologias gestoras da política de saúde, vêm se tornando ideais a serem criados pela educação contemporânea. Trata-se de um estilo de subjetividade forjada pelas práticas neoliberais recentes, nas últimas décadas, desde o final dos anos setenta, no século XX.

Foucault (2008a; 2008b) nos traz ferramentas analíticas para interrogar essas práticas de biocapital, tanto na política de saúde quanto na educação. 
Em O Nascimento da Biopolítica, o autor ressalta que as práticas de cuidado e de ensino cada vez são mais marcadas pelo ambientalismo-cognitivista e pela prevenção de riscos. Terapias genéticas, avaliação de casamentos e cuidados em saúde, pela ideia de investimento e empreendimento, são alvos de difusão e de grande adesão dos ávidos consumidores de produtos que prometem vida longa e jovialidade intensa, acopladamente ao aumento das performances individuais e coletivas de desempenho na educação, no trabalho, nos atos sexuais e nas relações afetivas.

O risco passa a ser negociado em termos de venda de serviços e estabelecimento de contratos, com cálculos de custo e benefício. Tornam-se cada vez mais comuns as judicializações da quebra desses acordos e igualmente da disputa dos mercados, de acessos aos direitos a diagnósticos e a medicamentos, bem como às cirurgias específicas. A tomada de decisão e as tensões que ela acarreta, no que concerne ao consumo e à regulamentação das tecnologias de gestão dos riscos, passam a gerar grande inquietação e a fomentar um mercado de seguros, conforme salienta Foucault.

A gestão do fazer viver e do deixar morrer é cada vez mais decisão de governo das condutas, a partir do biocapital, em uma economia política neoliberal. No Brasil, essa racionalidade anda "de vento em popa", na medida em que o país comemora os altos crescimentos dos mercados de medicamentos e das biotecnologias, como terapias e exames genéticos, pesquisas moleculares aplicadas à saúde patenteadas e indicadores crescentes de uma economia e infraestrutura aberta ao empresariamento da educação, da saúde e da pesquisa.

O Brasil passa a fechar acordos pelos BRICS com a China, a fim de realizar pesquisas aplicadas em desenvolvimento de diagnósticos e de tecnologias medicamentosas contra o câncer de pulmão, por exemplo, muito comum naquele país. O Brasil se espelha no mercado chinês das patentes, o qual cresceu aceleradamente e passa a buscar assinar acordos que potencializem a expansão da criação e de patentes também no país, como insígnia de um suposto processo de desenvolvimento econômico e social.

A inovação tecnológica é condição fundamental para o sucesso do processo relacionado aos sistemas produtivos. Cada vez mais empresas investem na criação de suas tecnologias. No entanto, para orientar as atividades de pesquisa, poupar tempo e evitar gastos desnecessários, a busca de informação em documentos de patentes é fundamental. A documentação de patente é a mais completa entre as fontes de pesquisa. Estudos revelam que $70 \%$ das informações tecnológicas contidas nestes documentos não estão disponíveis em qualquer outro tipo de fonte de informação. De acordo com a Organização Mundial 
da Propriedade Intelectual (OMPI), o número de pedidos de patentes tem crescido na ordem de 1,5 milhão a cada ano, que resultam em mais de 500 mil patentes concedidas. Empresas nos Estados Unidos, Japão e na Europa utilizam, cada vez mais, este instrumento como insumo estratégico. Com a preocupação de auxiliar o desenvolvimento tecnológico do País, o Centro de Disseminação da Informação Tecnológica (CEDIN) do INPI presta diversos serviços a empresas, instituições de pesquisa e inventores, além de realizar estudos em áreas estratégicas, através do acesso a um dos maiores acervos de informações sobre todos os tipos de tecnologias no mundo. O acesso a estas fontes de informação permite ampliar pesquisas, perceber tendências tecnológicas e monitorar o que está sendo desenvolvido e por quem. (BRASIL, 2014, s/p.).

Nesse mercado da saúde, os saberes são convocados a serem empregados no desenvolvimento dos países para geração das patentes e treinamento de pesquisadores que aceitem esse trabalho dócil e adestrado de perícia técnica e especialista do capital humano e biológico. O empresário de si e dos outros, no biocapital, se subjetiva por estilos biomédicos e farmacológicos, por gestões da educação em saúde e dos diagnósticos em prol da bioeconomia. Ter saúde é a mesma face de uma moeda de compra e venda de serviços biotecnológicos, que implica se submeter ao empresariamento da vida pelo governo das populações.

\section{Mercado da saúde no governo da vida: a biopolítica e o biocapital}

As disciplinas sobre os corpos e a biopolítica da população são tecnologias do saber-poder que não coincidem em relação à sua função, sua matéria e seus mecanismos; todavia, se encaixam e se complementam mutuamente na formação do que Michel Foucault (1999, p. 302) chama de sociedade da normalização, isto é, uma sociedade em que a norma da disciplina e a norma da regulação se estendem do orgânico ao biológico, “[...] mediante um jogo duplo das tecnologias de disciplina, de uma parte, e das tecnologias de regulamentação, de outra". Essa normalização não desaparece na racionalidade securitária, nela sendo incorporada como operador para ações sobre os corpos e sobre as vidas, em circulação local, nacional ou transnacional.

Nas sociedades securitizadas reguladas por intervenções biopolíticas, o biopoder visa a produzir forças, fazê-las crescer e ordená-las; esse poder tem por função regular as condutas humanas, objetivando manter e desenvolver a vida. A preocupação jurídica da soberania em vigiar, disciplinar e punir os corpos é rearticulada, na sociedade biopolítica, com a regulação biológica de uma população, uma vez que é sobre a vida e o seu desenvolvimento que o biopo- 
der estabelece seus pontos de fixação, de articulação e de maximização (FOUCAULT, 1988). O poder nunca chegou tão longe, no cerne da subjetividade e da própria vida, de sorte que já não sabemos “[...] onde está o poder e onde estamos nós, o que ele nos dita e o que queremos" (PELBART, 2008, p. 1).

A biopolítica marcou a entrada dos fenômenos próprios da vida nos cálculos e mecanismos de saber e poder da economia neoliberal (FOUCAULT, 1999, 2008a). Nessa política, autoridades compostas por uma variedade de especialistas assumem a responsabilidade pela administração da vida, para controlar, regular e modificá-la, a fim de promover e gerir o bem-estar, não somente individual, mas também coletivo (FOUCAULT, 1999; NOVAS, 2006). Para essa "virada", o neoliberalismo passa a ser fundamental para o desenvolvimento de um governo da vida e do capitalismo (FOUCAULT, 2008a).

Foucault (Ibid.), em $O$ Nascimento da Biopolítica, enfatiza que a lógica neoliberal de governar evidenciou uma economia de mercado que capitaliza todos os aspectos da vitalidade: educação, formação, alimentação, aspectos genéticos, o número de horas que os pais gastam com seu filho. Todas essas condições de vida se tornam rentabilizadas para a constituição de um capital humano, cujo lucro é direcionado para o futuro. Contemporaneamente, a visão econômica neoliberal predomina, e a lógica dos mercados globalizados sustenta vigorosamente seu poder e influência (CARDOSO; CASTIEL, 2003).

$\mathrm{O}$ mercado tende a abrir-se para as parcerias internacionais e permite que empresas transnacionais exerçam influência nas políticas de desenvolvimento dos países nos quais instalaram suas filiais. No Brasil, esse modelo de mercado tem sua origem no final dos anos 1980, quando medidas de modernização do Estado visavam a duas estratégias específicas: a abertura do mercado para transações multinacionais e a privatização de empresas públicas (CERVO, 1997).

Tal cenário se desenvolve com base em políticas macroeconômicas de cunho neoliberal, assinaladas pela globalização financeira, na qual investimentos estrangeiros dos denominados países desenvolvidos são realizados em países considerados periféricos, bem como pela reestruturação produtiva de grandes empresas, por meio da utilização de tecnologias da informação (WOLFF, 2014).

Esse duplo traço do mercado - sua tendência a suplantar os limites das fronteiras nacionais e sua tendência à privatização - acaba por moldar, pela biopolítica, as sociedades regulamentadoras contemporâneas: a biopolítica facilmente ultrapassa os limites de qualquer governo nacional, amalgamando-se sem dificuldades a qualquer estirpe ideológica, ao mesmo tempo em que molda toda ação política, transformando-a em econômica, isto é, transformando o espaço e toda a vida política em uma vida de gestão e administração, coerente 
a um estado de polícia (L'HEUIELLET, 2001). As consequências dessa redução econômica da vida política, engendrada pela biopolítica, consistem em uma reconfiguração discursiva da vida ao âmbito do privado e do individual - em termos de desfiliação - e de que todos os aspectos vitais passam a ser valorados em termos financeiros.

As estratégias de regulação da economia de mercado brasileiro têm demonstrado o modo como nós somos governados, em que prerrogativas do consumidor são instituídas para que ele possa exercer seu "direito" de ser informado e ter "liberdade" de escolher tecnologias e conhecimentos, visando a proteger sua saúde e ampliar seu bem-estar (CARDOSO; CASTIEL, 2003).

Vale lembrar que essa liberdade não impede o aparelho policial de reprimir as desordens, as delinquências (TÓTORA, 2011). Em lugares como, por exemplo, o Brasil, é comum visualizarmos uma forma de guerrilha que se tornou mal disfarçada e cotidiana, reinstituída nas desigualdades econômicas e sociais, nos eventos cada vez menos incomuns de violência urbana, os quais se relacionam muitas vezes a ações prepotentes de instituições oficiais encarregadas pela segurança (CASTIEL, 2010).

$\mathrm{Na}$ arte neoliberal de governar, o Estado assume a característica de uma tecnologia humana que gere a conduta dos outros: governar é agir sobre as pessoas que devem ser consideradas como livres num estado pretensamente democrático. Foucault (2008a) salienta que as sociedades liberais surgiram, quando problemas relativos à saúde, higiene, natalidade, longevidade, raças não podem ser dissociados do âmbito da racionalidade política e da normalidade, no interior da qual eles aparecem e adquirem importância e intensidade. Avelino (2013) sublinha que o liberalismo é uma filosofia política, caracterizada pelos limites que impõe ao poder exercido pelas autoridades políticas.

De acordo com Tótora (2011), a liberdade se torna exigência da própria governamentalidade, na medida em que a arte de governar a população requer que se respeitem, em tese, algumas liberdades. Contudo, essa liberdade mantém-se presa a uma democracia de baixo impacto ou presa das regulações das corporações transnacionais; uma liberdade que, dificilmente, coincide com qualquer direção democrática, como diagnostica Passetti (2011), exceto a de feição neoliberal, na qual prevalece o modelo econômico-financeiro em que a liberdade é reduzida à mercadoria e não por sua pertinência política, social e ética. E a vida que, para os pensadores liberais clássicos, era propriedade inviolável do indivíduo, se torna, nos regimes neoliberais contemporâneos, meros produtos econômicos (BROSSAT, 2003; 2010).

Assim, pensando no modo contemporâneo de produção do capital, Lazzarato (2004) argumenta que o capitalismo produz sujeitos e objetos em varia- 
ção contínua, modulada por tecnologias de gestão da vida. Para ele, o controle da sociedade capitalista ocidental integra formas de controles disciplinares do Estado de bem-estar com controles inscritos por empresas, através de sinais, palavras e imagens, as quais afetam as pessoas, seus corpos e subjetividade, produzindo mundos comuns e suas diferenciações, simultaneamente.

Pelbart (2008) enfatiza que as sociedades neoliberais não precisam apenas de músculos e disciplinas, mas de imaginação, de inventividade e da própria vitalidade. Ou seja, a fonte de riqueza é a inteligência das pessoas, sua criatividade, sua afetividade e, principalmente, seu corpo e o seu desenvolvimento saudável. É assim que, para Lazzarato (2013), os investimentos na criança, mensuráveis em tempo, constituirão uma renda salarial, quando ela se tornar adulta, de sorte que, para os pais que investiram tempo na educação do seu filho, haverá uma satisfação, um benefício psicológico pela formação de um adulto produtivo.

Abordando as estratégias biopolíticas contemporâneas, Rose (2011) ressalta que, na economia neoliberal, se acentua a emergência de um biocapital o qual traz à tona um novo espaço empresarial como potencial terapêutico. Vidas-investimento se tornam uma modalidade de subjetivação prevalente e dirigida, persecutoriamente, ao futuro. É a esperança que está em jogo, e esta supõe uma interação entre o presente e o futuro, uma vez que ter esperança significa realizar ações direcionadas à construção de possíveis futuros desejáveis. Esperança, cautelas e precauções organizam a vida das pessoas, visando a um futuro melhor; ela é individual e coletiva, dado que permite a união de biografias individuais com interesses coletivos, processos sociais, econômicos e políticos (NOVAS, 2006).

No entanto, é preciso fazer aqui uma ressalva: o aspecto coletivo da vida, da existência vital, não decorre da possibilidade democrática ou mesmo republicana de que se pensa e se vive coletivamente, mas do fato de que parcela significativa das pessoas pensa "coletivamente" apenas em seu favorecimento pessoal e em sua proteção contra todas as adversidades que porventura possam acometê-las, bem numa perspectiva imunitária (BROSSAT, 2003; ESPOSITO 2009), coincidente com a crescente mercantilização da vida e da liberdade, em tempos neoliberais.

As reflexões sobre o biocapital vêm apresentando ainda uma mudança na forma de conceber a ciência. Se, antes, tínhamos uma ciência restrita a poucos e permeada de práticas biopolíticas liberais, agora ela se mistura a outros campos considerados não científicos até então, e arregimenta uma política neoliberal permeada por práticas de valor, as quais mobilizam socialidades articuladas a discursos de afetividade, esperanças e precauções. 
Nas políticas neoliberais, o direito à saúde e às práticas de formação de corpos é extremamente capitalizado e estratificado, e as liberdades são constantemente colocadas como encomendas para agenciamentos de subjetivação, notadamente aquelas formas de sujeição do indivíduo comprometedoras, constrangedoras e limitadoras de todas as formas livres e criativas (portanto, não sujeitadas) de atualização da subjetividade. Waldby (2000) propôs o termo biovalor para referir-se, justamente, a esse capital que surge quando a produtividade gerativa e transformativa das entidades vivas pode ser instrumentalizada de maneira útil para projetos em ciência, indústria, medicina e outras arenas da cultura técnica e econômica.

Esse campo do chamado biovalor procura dar conta dos modos pelos quais a própria vitalidade tem se tornado uma fonte de capitalização. As subjetivações se tornam elemento indispensável na política que configura as sociedades liberais do século XVIII e XIX, e nas neoliberais de nossos dias (AVELINO, 2011). Desenham-se, simultaneamente, vidas investimento, nas tramas da securitização, e vidas como direito, nas democracias de baixo impacto do neoliberalismo.

Nossas subjetividades estão cada vez mais marcadas pela interiorização dentro de moléculas, genes, células, tal qual aquela que marcou o nascimento da clínica e a instauração de um novo olhar médico sobre os sinais do corpo, bem como a interiorização de nossas impressões digitais pelas expertises forenses. Hoje, os biotécnicos dizem, em grande parte, quem somos e quais responsabilidades e direitos temos; são os novos oráculos nos quais somos devorados pelas encomendas de novas formas de vida, criadas através da afetação de tecnologias médicas sobre o corpo, as quais estabelecem normas de uma boa saúde.

Conforme Anderson (2012), aprendemos, com as políticas voltadas para a própria vida, que, para proteger, cuidar e manter as vidas, é preciso investir e prever os danos. A gestão do risco e da vigilância, em aliança, força a instauração de formas de capital genético que estão mudando as relações entre saúde e patologia, doença e cura, tecnociência e corpo, e a regulação das políticas públicas e da saúde privada. Assim, novas tecnologias de saúde são organizadas na imanência, isto é, na correlação ao acaso de forças com as mutações do mercado, com as transformações das famílias, com os efeitos ecológicos dos impactos ambientais, com as alterações da política e com a atualização das relações sociais e culturais.

Com efeito, a subjetividade é um território de existência que torna atual o virtual e que torna extensas as matérias intensivas. As forças dos agenciamentos subjetivos são compostas por subjetivações, processos ininterruptos 
que não cessam de fazer vibrar e atravessar a dobra provisória da subjetividade, fazendo-a estremecer e pedindo passagem em atualizações as quais materializem os efeitos das afetações sofridas, conforme pensou Gilles Deleuze (1992), a propósito das sociedades de controle. As modulações de subjetivação se organizam como forças em agenciamentos coletivos que operam, por correlações sem causalidade e sem linearidade, na esfera dos acontecimentos que se cruzam e se conectam como teias, sem privilégio de entradas e saídas das suas linhas de composição.

\section{Mercado liberal da saúde e gestão da segurança}

Foucault havia afirmado, em O Nascimento da Biopolitica (2008a) e em Segurança, território e população (2008b), que os poderes pastorais, ou seja, os governos de condutas em nome da salvação eterna, foram transformados em modos de gerir para salvar a saúde e forjar um mercado de tecnologias potencializadoras da vida enquanto empresas-empreendimentos performáticos. Castel (1987), por seu turno, assinala como as políticas de saúde e educação, da segunda metade do século XX em diante, foram ganhando feições de gerência de riscos em nome da segurança e da produção de altas performances de rendimento, em um mercado da saúde e do cuidado preventivo desde a tenra infância. Nesse aspecto, governamentalidade conformou-se como um

\footnotetext{
[...] conjunto constituído pelas instituições, procedimentos, análises e reflexões, cálculos e táticas que permitem exercer essa forma bastante específica e complexa de poder, que tem por alvo a população, como forma principal de saber a economia política e por instrumentos técnicos essenciais os dispositivos de segurança (FOUCAULT, 1979, p. 291-292).
}

No mercado da saúde atual, discursos esperançosos quanto a um futuro imune de patologias e a expectativa do aumento da longevidade são alguns dos motivos que impulsionam e movimentam grande parte das atividades do biocapital. A esperança pode ser pensada com base no que Foucault (2008b) denominou controle social pelo dispositivo de segurança.

A vida afetiva das pessoas é alvo e condição para novas formas contemporâneas de governamentalidade (ANDERSON, 2012), nas quais relações de afeto e amor são ferramentas de poder e controle dos corpos e arregimentam a capitalização da vida. Sentimentos de esperança, amor, segurança são invocados para convencer pais amedrontados a recorrerem às técnicas em medicina molecular, como estratégias de proteção aos seus filhos (GALINDO; LEMOS; RODRIGUES, 2014). 
Enquanto consumidores de serviços, convocados a sermos livres, estamos cada vez mais envolvidos nas tramas discursivas e não discursivas que configuram retóricas salvacionistas, laicizando antigas apostas no domínio do sagrado (HARAWAY, 1995). As biomedicinas e suas técnicas desempenham, neste tempo, um papel importante na modulação das subjetividades (ROSE, 2013), caracterizadas pelo medo, estes últimos cruciais para a continuidade do investimento na segurança que passa a ser investimento na própria vida (CASTIEL; ÁLVAREZ-DARDET, 2007a).

O surgimento do governamentalidade neoliberal, “[...] na reflexão de Foucault, indica significativas transformações nas práticas de governo de pessoas, populações e da circulação de coisas" (RODRIGUES, 2013 p. 136). O Estado e a sociedade têm por função regular a vida e a saúde, a fim de administrar as condutas das pessoas sem destruir a sua existência e autonomia, o que é possível por meio da proliferação de especialistas (MILLER; ROSE, 2012).

Tais alianças, no entanto, têm que ser consideradas com muita cautela. Elas não são gratuitas e nem mesmo naturais, por mais que se cerquem de discursos legitimadores em prol de sua naturalização, que tem como um de seus efeitos o de neutralizar qualquer crítica ou divergência aos representantes dos mercados internacionais e de rotinas de expertises estabelecidas por organizações corporativo-profissionais. Muitas dessas alianças revestem fomentos e acordos financeiros os quais objetivam propagandear determinado conjunto de condutas e procedimentos plenamente administráveis e rentáveis quer do ponto de vista político, quer do ponto de vista econômico. Qualquer comportamento, qualquer forma de vida que escape e divirja dos padrões previamente regulamentados tendem a ser desqualificados, gerando discriminações e desigualdades diversas (FASSIN, 2007).

Prever e admitir riscos, estabelecer limites e regulamentar as práticas, para evitar futuras doenças, materializam as práticas salvacionistas fixadas pela lógica preventivista e securitária em saúde, no cotidiano das pessoas, constituindo dever de um Estado definido pelas modulações das práticas mercadológicas:

Já não há problema social que não seja tratado em termos de risco; higiene, saúde, poluição, inadaptação, delinquência. E a instituição da segurança social faz do seguro a própria forma da relação social. Movimento geral senão de normalização, pelo menos de normativação a partir da tecnologia do risco. Tal como não há norma que não seja social, não poderia existir norma isolada. Uma norma nunca se refere senão a uma outra norma da qual, por isso mesmo, depende. As normas comunicam entre si, de um nível ou de um espaço a outro, de acordo 
com uma espécie de lógica modular. Uma norma encontra o seu sentido numa oura norma: só uma norma pode dar valor normativa a outra norma (EWALD, 1993, p. 106-107).

Essa prática de retórica artefactual-social fabrica mundos e muda a forma de saber e poder sobre objetos novos - como os genes, as células-tronco do cordão umbilical. O que não é de espantar, pois, como aponta Haraway (1995, p. 10), a própria Ciência é retórica, “[...] é a convicção de atores sociais relevantes de que o conhecimento fabricado por alguém é um caminho para uma forma desejada de poder bem objetivo".

\section{Empresariamento e endividamento, conclusões que prefaciam}

O empreendedorismo de si tem lugar numa cultura marcada pela família medicalizada e medicalizante, em que prevenir doenças e garantir práticas de lidar com elas impulsiona um mercado modulado por investimentos na relação pais e filhos. Foucault (2008a) já apontava que, sendo a principal característica da biopolítica sua visão voltada para o futuro, estratégias de regulação são criadas para possibilitar intervenções na direção de reformatar o futuro da saúde humana, atuando no presente vital.

Aliados às estratégias biopolíticas, os ideários de autoconsciência de ser saudável e a saúde perfeita tornaram-se novos paradigmas em nossas sociedades neoliberais atuais (ORTEGA, 2004). Estamos em dívida constante, pois, como os empresários, jogamos num mercado de ativos, numa bolsa de valores que nos devolve pouco mais que incertezas menos desproporcionais.

Castiel e Álvarez-Dardet (2007b, p. 59) assinalam que permanecemos no regime dos riscos característico da biopolítica traçada por Michel Foucault, porém, este é acrescido do regime da precaução, em que cálculos probabilísticos se somam a uma panóplia de aparatos de vigilância, monitoramento e promoção de saúde. Ou, ainda, movidos por medos paranoicos que sustentam o investimento em vidas empresariais, as quais se tornam, em certa medida, alheias a nós mesmos como projetos a cumprir e gerenciar, uma expropriação daquilo que vem sendo entendido como "vida própria" por concernir aos processos vitais.

Instaura-se, igualmente, constante endividamento com as empresas que ofertam serviços cujo pagamento se dá por crédito parcelado ou que requerem manutenção dos materiais biológicos ofertados, na forma de pagamentos mensais, sendo esta uma faceta introduzida pelo mercado neoliberal em nossas vidas, a qual se torna muito clara nas camadas médias brasileiras que 
acessam serviços de criopreservação de materiais biológicos, no Brasil. Tais serviços também têm buscado se expandir, como o fizeram as cirurgias plásticas, por meio de parcelamento e pacotes vendidos a grupos, ampliando o número de potenciais consumidores.

O estímulo ao consumo ultrapassou as barreiras impostas pela necessidade de controle e segurança na utilização de "produtos de saúde". O discurso mercadológico, através de instrumentos educativos e de informação, forja o surgimento de um mercado consumidor no seio do exercício do direito ao acesso, seja ao produto, seja à informação. No ramo da farmacoeconomia, o relacionamento entre o consumidor e a indústria tem prescindido cada vez mais da intermediação do prescritor. A informação, como um instrumento de mercado, não se limita a difundir conhecimento sobre um produto, mas o vende, como um tratamento (BARROS, 2004).

Segundo Freud e Ramirez (2014), “[...] a deseasemongering (promoção de doenças) é uma estratégia da indústria farmacêutica que cria condições adequadas para os seus alvos comerciais". Desse modo, as informações sobre as doenças são fornecidas juntamente com os medicamentos indicados para o seu tratamento. O uso de recursos amplamente acessíveis de informação, com vistas à ampliação do mercado de produtos para a saúde, é tema recorrente na área bioética. $\mathrm{O}$ conflito de interesses envolvido na disseminação de informações "de saúde" permeia as relações entre médicos e a indústria de medicamentos; a escolha pela droga que será prescrita pode ser motivada pela "[...] retribuição à gentilizas e favores recebidos" pelo profissional (MASSUD, 2010).

Concluamos, com o diagnóstico de Lazzarato a respeito dessa mutação nas subjetividades. Entra em cena, além das desigualdades entre contratantes e contratados, as assimetrias entre credores e endividados. Trabalhadores, consumidores, endividados, adverte o autor sobre o que se prefacia a respeito do que estamos em via de nos tornarmos:

De certo ponto de vista é o mesmo: há desigualdade entre patrão e operário, como entre credor e devedor. O problema é que hoje os credores não se definem de uma classe social específica. A condição de credor concerne também à classe média, aos operários. Os fundos de pensão foram privatizados. Para sua velhice, o sujeito adquire um seguro privado. Quanto à subjetividade do devedor, Nietzsche trabalhou a questão da promessa. Diz que o que formou o homem civilizado não é o trabalho, nem o intercâmbio, e sim, a dívida. Porque a dívida constrói um homem que pode prometer, e pode prometer enquanto constrói uma memória: eu vou pagar porque lembro da minha dívida. A dívida, a promessa, estão marcadas no corpo do indivíduo como a libra de carne de $O$ Mercador de Veneza. O que 
me interessa destacar é que um indivíduo é ao mesmo tempo trabalhador, consumidor e devedor. A mesma pessoa está presa em diferentes relações de poder (LAZZARATO, 2011).

No neoliberalismo, tornamo-nos empresários de nossas vidas, sendo nosso próprio capital e fonte de renda (FOUCAULT, 2008a), pois o mercado não é definido pelos instintos do homem em fazer troca. Por mercado entende-se uma relação de concorrência e desigualdade, na qual os sujeitos não são comerciantes, mas empresários (LAZZARATO, 2013).

Nesse sentido, a força de trabalho deixa de ser a moeda principal de troca do ser humano. Passa a gerenciar e comercializar, também, os seus processos vitais biológicos - sob a forma de propriedade, patrimônio, pluripotência - como empresa e centro biomédico, visando a melhorar sua saúde e, consequentemente, a aumentar longevidade, sendo este o caso do empreendedorismo como estilo de vida, no campo dos processos de subjetivação ou ainda almejando a comercialização nos circuitos de biopauperização.

Os mercados na China e Índia mobilizam intensos fluxos financeiros do chamado turismo biológico. Esses mercados comportam dos aluguéis de úteros à comercialização de órgão e dos tecidos. Há ainda o mercado das patentes, que também cresce na China assustadoramente, assim como vem aumentando a chamada medicina personalizada, baseada em diagnósticos moleculares e genéticos para gerir riscos de câncer, por exemplo.

Nesse mercado da saúde, os saberes são convocados a serem utilizados no desenvolvimento dos países para geração das patentes e treinamento de pesquisadores os quais aceitem este trabalho dócil e adestrado de perícia técnica e especialista do capital humano e biológico.

O empresário de si e dos outros, no biocapital, se subjetiva por estilos biomédicos e farmacológicos, por gestões da educação em saúde e dos diagnósticos em prol da bioeconomia. Ter saúde é a mesma face de uma moeda de compra e venda de serviços biotecnológicos, que implica se submeter ao empresariamento da vida pelo governo das populações.

\section{Referências}

ANDERSON, Ben. Affect and biopower: towards a politics of life. Trans Inst Br Geogr, v. 37, p. 28-43, 2012.

AVELINO, Nildo. Democracia e educação na constituição do sujeito liberal. Educação, Porto Alegre, v. 36, n. 2, p. 180-191, 2013. 
Governamentalidade e democracia liberal: novas abordagens em Teoria Política. Revista Brasileira de Ciência Política, Brasília, DF, n. 5, p. 81-107, 2011.

BRASIL. (INPI - Instituto Nacional de Propriedade Industrial) Guia - Informação Tecnológica. CGCOM, 27 jan. 2015. Disponível em: < http://www.inpi.gov.br/portal/artigo/guia informacao tecnologica> 2014. Acesso em: 18 nov. 2014.

BROSSAT, Alain. Droit à la vie? Paris: Seuil, 2010.

La démocratie immunitaire. Paris: La Dispute, 2003.

CARDOSO, Maria; CASTIEL, Luiz. Saúde coletiva, nova genética e a eugenia de mercado. Cad. Saúde Pública, Rio de Janeiro, v. 19, n. 2, p. 653-662, 2003.

CASTEL, Robert. Gestão de riscos: da pós-psiquiatria à pós-psicanálise. Rio de Janeiro: São Francisco, 1987.

CASTIEL, Luiz.; ÁLVAREZ-DARDET, Carlos. La Salud persecutória. Rev Saúde Pública, São Paulo, v. 41, n. 3, p. 461-466, 2007a.

. A saúde persecutória: os limites da responsabilidade. Rio de Janeiro: Fiocruz, 2007b.

Risco e hiperprevenção: o epidemiopoder e a promoção da saúde como prática biopolítica com formato religioso. In: NOGUEIRA, Roberto (Org.). Determinação social da saúde e da reforma sanitária. Rio de Janeiro: Cebes, 2010. p. 161-179.

CERVO, Amado. Política de comércio exterior e desenvolvimento: a experiência brasileira. Rev. Bras. Polit. Int., v. 40, n. 2, p. 5-26, 1997.

DELEUZE, Gilles. Conversações. Rio de Janeiro: Editora 34, 1992.

ESPOSITO, Roberto. Immunitas. Protección y negación de la vida. Buenos Aires: Amorrortu, 2009.

EWALD, François. Foucault, a Norma e o Direito. Lisboa: Vega, 1993.

FASSIN, Didier. When bodies remember: Experiences and politics of AIDS in South Africa. Berkeley: University of California Press, 2007.

FOUCAULT, Michel. Microfísica do poder. Petrópolis/RJ: Vozes, 1979.

. História da Sexualidade I: a vontade de saber. Rio de Janeiro: Graal, 1988.

. Em Defesa da Sociedade. São Paulo: Martins Fontes, 1999.

. O Nascimento da Biopolitica. São Paulo: Martins Fontes, 2008a.

. Segurança, território e população. São Paulo: Martins Fontes, 2008b.

FREUD, Joseph. Sobre O TDAH: Transtorno ou invenção? Cienc. Cult. São Paulo, v. 66, n. 1, p. 54-57, 2014. 
GONZÁLEZ, Carlos. et al. The Bioeconomy: a new perspective of the Economic. In: RED CYTED, Red de Bioeconomía y Cambio Climático (REBICAMCLI) (Org.). Estado del arte de la bioeconomía y el cambio climático. Universidad Nacional Autónoma de Nicaragua: Editorial Universitaria, 2014.

HAMILTON, Chris. Intellectual property rights, the bioeconomy and the challenge of biopiracy. Genomics, Society and Policy, v. 4, n. 6, p. 26-45, 2008.

HARAWAY, Donna. Saberes localizados: a questão da ciência para o feminismo e o privilégio da perspectiva parcial. Cadernos Pagu, n. 5, p. 07-41, 1995.

. Testigo_Modesto@Segundo_Milenio._Lectora, revista de dones i textualitat, [S.1.], n. 10, p. 13-36, 2004.

When Species Meet. London: University of Minnesota Press, 2008.

LAZZARATO, Maurizio. From capital-labour to capital-life. Ephemera, [S.1.], v. 4, n. 3, p. 187-208, 2004.

. Atualmente vigora um capitalismo social e do desejo. Entrevista com Maurício Lazzarato. Instituto Humanitas Unisinos. Disponível em: http://www.ihu.unisinos.br/noticias/ 39543-atualmente-vigora-um-capitalismo-social-e-do-desejo-entrevista-com-maurizio-lazzarato. 2011. Acesso em: 18 nov. 2014.

. Biopolítica/Biocapital. In: PASSOS, I. C. F. (Org.). Poder, normalização e violência: incursões foucaultianas para a atualidade. 2. ed. Belo Horizonte: Autêntica, 2013.

L'HEUILLET, Hélene. Basse politique, haute police: une approche historique et philosophique de la police, Paris: Fayard, ¡2001.

MASSUD, Munir. Conflito de interesses entre médicos e a indústria farmacêutica. Revista Bioética, [S.1.], v. 18, n. 1, p. 75-91, 2010.

MIGNOLO, Walter. Novas reflexões sobre a "idéia da América Latina": a direita, a esquerda e a opção descolonial. Caderno CRH, Salvador, v. 21, n. 53, p. 239-252, 2008.

MILLER, Peter: ROSE, Nikolas. Governando o presente: gerenciamento da vida econômica, social e pessoal. São Paulo: Paulus, 2012.

NOVAS, Carlos. The political economy of hope: patients' organizations, Science and biovalue. BioSocieties, [S.1.], v. 1, p. 289-305, 2006.

ORTEGA, Francisco. Biopolíticas da saúde: reflexões a partir de Michel Foucault, Agnes Heller e Hanna Arendt. Interface - Comunic., Saúde, Educ., Botucatu, SP, v. 8, n. 14, p. 9-20, 2004.

PELBART, Peter Pal. Vida e morte em contexto de dominação biopolítica. In: CICLO "O Fundamentalismo Contemporâneo Em Questão" [Conferência proferida no dia 3 de outubro de 2008], São Paulo. Anais... São Paulo: IEA/USP, 2008, p. 1-21.

PRADO-FILHO, Kleber. Uma genealogia das práticas de normalização nas sociedades ocidentais modernas. In: CAPONI, S.; VERDI, M.; BRZOZOWSKI, F. S.; HELMANN, F. 
(Org.). Medicalização da Vida: Ética, Saúde Pública e Indústria Farmacêutica. Palhoça: Unisul, 2010, p. 183-191.

RODRIGUES, Thiago. Ecopolítica e segurança: a emergência do dispositivo diplomático-policial. Revista Ecopolítica, São Paulo, n. 5, p. 115-156, 2013.

ROSE, Nikolas. Biopolítica molecular, ética somática e o espírito do biocapital. In: SANTOS, L. H. S.; RIBEIRO, P. R. C. (Org.). Corpo, gênero e sexualidade: instâncias e práticas de produção nas políticas da própria vida. Rio Grande: FURG, 2011. p. 13-32.

. A política da própria vida: biomedicina, poder e subjetividade no século XXI. São Paulo: Paulus, 2013.

TÓTORA, Silvana. Foucault: Biopolítica e governamentalidade neoliberal. REU, Sorocaba, v. 37, n. 2, p. 81-100, 2011.

WALDBY, Catherine. The Visible Human Project: informatic bodies and posthuman medicine. London and New York: Routledge, Taylor \& Francis Group, 2000.

. Oöcyte markets: global tissue economies and women's reproductive work in embryonic stem cell research. New Genetics and Society, University of Sydney NSW, 2006.

WOLFF, Simone. Desenvolvimento local, empreendedorismo e "governança" urbana: onde está o trabalho neste contexto? Caderno CRH, Salvador, v. 27, n. 70, p. 131-150, 2014.

Submissão em: 17/12/2014

Revisão em: 28/01/2015

Aceite em: 21/01/2015

Renata Rodrigues é mestre em Estudos da Cultura Contemporânea/UFMT. E-mail: renatinha.vilela@gmail.com

Dolores Galindo é psicóloga/UFPE. Mestre e Doutora em Psicologia social/PUC-SP. Profa.de Psicologia Social. Docente no Programa de Pós-graduaçãode Estudos da Cultura Contemporânea. Universidade Federal de Mato Grosso - UFMT. Endereço: Instituto de Linguagens / ECCO. Av. Fernando Corrêa da Costa, n 2367, sala 44/IL. Bairro Boa Esperança. Cuiabá/MT, Brasil. CEP 78060-900 E-mail: dolorescristinagomesgalindo@gmail.com

Flávia Cristina Silveira Lemos é psicóloga/UNESP. Mestre em Psicologia Social/ UNESP. Doutora em História/UNESP. Bolsista de produtividade em pesquisa CNPQ2. Profa. adjunta IV de Psicologia social/UFPA. E-mail: flaviacslemos@gmail.com 
Marcos Nalli é filósofo. Mestre em Psicologia/UEM e Doutor em Filosofia/UNI-

CAMP. Prof. de filosofia/UEL na graduação e na pós-graduação. E-mail: marcosnalli@yahoo.com.br

Daniella Soares dos Santos é doutora em Ciências/USP. Profa. de Saúde do Adolescente - Faculdade de Ciências da Saúde/UnB. Líder do Grupo de Pesquisa Adolescência, Psicopathologia e Psicanálise. E-mail: daniellasoares@unb.br 